\title{
PERCEPÇÕES DE PROFESSORES DE LÍNGUA INGLESA SOBRE OS USOS DA TECNOLOGIA E DA INTERNET NA APRENDIZAGEM DE LÍNGUA ESTRANGEIRA
}

Rosi Ana GRÉGIS ${ }^{1}$

Resumo: O objetivo principal deste trabalho é discutir as percepções de professores de inglês como língua estrangeira acerca de como a internet e as novas tecnologias têm influenciado na aprendizagem de línguas, tanto em sala de aula como em ambientes informais de aprendizagem. Autores como Zhao (2005), Lai (2005) e Stanley (2013) percebem que o uso de blogs, chats, Twitter, e-mails, sites e vídeos da internet, entre outros, podem contribuir para uma aprendizagem mais eficaz da língua inglesa. Portanto, não é surpresa observar que, nesta pesquisa, a maioria dos professores de inglês entrevistados acredita que as novas tecnologias podem mudar a maneira como se aprende e se ensina línguas estrangeiras.

Palavras-chave: Aprendizagem de línguas; Tecnologia; Internet.

\section{Introdução}

O uso de tecnologias não é algo novo na aprendizagem de línguas estrangeiras. ${ }^{2}$ Principalmente a partir da década de 60, professores já dispunham de discos de vinil, fitascassete, fitas de vídeo e, a partir da década de 90, CDs e DVDs para trabalhar as quatro habilidades linguísticas. Com isso, esses profissionais foram ficando mais hábeis e mais seguros à medida que utilizavam aparatos tecnológicos cada vez mais rápidos e eficientes no auxílio às tarefas realizadas em sala de aula. Conforme Zhao (2005), muitas pesquisas nessa

\footnotetext{
${ }^{1}$ FEEVALE - Universidade Feevale - Instituto de Ciências Humanas, Letras e Artes. Novo Hamburgo - Rio Grande do Sul - Brasil. 93534-040 - rosiana@feevale.com.br

${ }^{2}$ Utilizaremos os termos segunda língua (L2) e língua estrangeira (LE) para nos referirmos a qualquer outra língua que não a língua materna, adquirida ou aprendida tanto em meio formal quanto em quaisquer outros ambientes. Destacamos que o foco deste trabalho é a aprendizagem de inglês por brasileiros adultos (a partir de 14 anos).
} 
área demonstram que a tecnologia pode realmente auxiliar na aprendizagem. Na verdade, não é necessário sermos especialistas em software ou informática para percebermos a gama de opções que temos à mão para dar suporte às nossas aulas: apenas com o uso de um computador ou telefone celular conectado à internet, podemos trabalhar com vídeos, hipertextos, músicas, atividades gramaticais e de desenvolvimento de vocabulário, além de pesquisar sobre assuntos variados, tais como história, política, geografia, arte e cultura dos lugares mais inusitados possíveis.

Mesmo assim, as pesquisas na área são incipientes, e os professores muitas vezes podem se sentir inseguros sobre como usar tantas novidades em sala de aula, embora computadores sejam usados em aulas de língua estrangeira (LE) de diversas formas já há algum tempo. Essas atividades são realizadas com o auxílio de editores de textos, programas para criar edições gráficas como Power Point, câmera de foto, filmadora, entre outros recursos. A internet, por outro lado, está sendo introduzida em sala de aula paulatinamente: nem todas as escolas possuem conexão com banda larga, e, além disso, os professores estão começando a se familiarizar com todas as possibilidades que a internet pode oferecer no auxílio e na produção de tarefas. A internet pode ser considerada umas das maiores revoluções deste século, pois é uma rede que agrupa milhões de computadores em todo o mundo, de todos os tipos e com diferentes sistemas operacionais. Milhares de informações são adicionadas em tempo real, e o resultado disso é uma impressionante quantidade de dados sobre qualquer assunto imaginável.

Embora o acesso à internet esteja disponível a milhões de pessoas em todo o mundo, somente nos últimos anos educadores têm se dado conta da sua importância e do potencial que ela traz para o ensino formal, desde troca de e-mails até a comunicação feita através de chats, blogs, Twitter etc. Segundo Kroonenberg (1995), uma das vantagens da internet é fazer com que aprendizes mais inibidos sejam encorajados a trocar mensagens, se beneficiando de uma interação significativa e eficaz com falantes nativos da língua alvo ou falantes da sua língua materna. $\mathrm{O}$ fato de não precisar se expor frente a frente com outra pessoa faz com que aprendizes tímidos se coloquem em uma perspectiva mais corajosa diante de outros falantes e do professor. Quanto à troca de e-mails, Kroonenberg (1995) salienta que a internet oferece incontáveis assuntos de interesse dos aprendizes, oferecendo então mais possibilidades de os alunos escreverem sobre o que gostam, articulando melhor suas ideias, e assim produzindo mais textos escritos. Em uma pesquisa realizada por esse autor, os aprendizes declararam escrever mais e estarem mais envolvidos nas tarefas com e-mails por se interessarem por assuntos abordados e assim terem mais vontade de se manifestar através da escrita. De acordo 
com Kroonenberg (1995), isso permite que cada aluno manifeste sua opinião, em discussões nas quais todos são ouvidos, já que isso nem sempre acontece em debates orais em sala de aula. Sendo assim, a internet oferece muitas formas de interação e troca de informações que vão além do uso de e-mails ou blogs. A World Wide Web integra informações de maneira eficaz e podemos acessá-la de maneira simples e rápida, em qualquer parte do mundo.

Simplesmente não há mais como não integrarmos essa rede no ensino de qualquer disciplina. É importante que a cada dia mais educadores agreguem a internet a suas aulas, sempre que possível, oferecendo a seus alunos maiores chances de se atualizarem quanto ao uso de uma tecnologia presente em grande parte dos setores profissionais e educacionais. Nesta pesquisa, particularmente, temos o objetivo principal de apresentar as percepções de 87 professores, com experiência profissional e faixa etária diversas, sobre questões relativas ao uso de tecnologias - principalmente a internet - e a aprendizagem da língua inglesa no Brasil.

\section{Aprendizagem de inglês como segunda língua e o uso de tecnologias}

Nas últimas décadas, com inúmeros avanços tecnológicos e principalmente com o advento da internet - no Brasil, ocorreu no final dos anos 80 -, há uma gama de equipamentos que podemos usar para enriquecer nossas aulas e motivar nossos alunos: tablets, telefones celulares, câmeras, filmadoras, projetores, $d v d s$, blu-rays, quadros interativos etc. A tecnologia, em sala de aula, não deveria ser algo usado esporadicamente, mas fazer parte da maioria dos planos de aula de língua estrangeira (LE). Stanley (2013) salienta que não devemos utilizar somente computadores com internet, mas também auxiliar os aprendizes a usar seus próprios celulares para acessar dicionários, thesaurus, tabelas fonéticas, vídeos legendados, letras de suas músicas favoritas, sites sobre cultura, história, geografia, artes e quaisquer outros assuntos de interesse. $\mathrm{O}$ autor reforça que um dos maiores obstáculos que os professores enfrentam é o medo de que algo dê errado com os equipamentos tecnológicos, fazendo com que muitos optem por não usar a tecnologia em aula. Stanley (2013) sugere que o professor tenha sempre um "plano B", caso aconteça algo diferente do esperado. Na verdade, não há mais como voltarmos atrás: nossa vida está cercada pela tecnologia e o computador faz com que economizemos tempo em tarefas que antes demorávamos muito para realizar.

Além disso, poder acessar informações em tempo real e sobre qualquer assunto é algo surpreendente. Isso faz com que o uso de novas tecnologias e da internet seja uma ferramenta de muita interatividade. A internet, sem dúvida, se tornou o maior fenômeno social e está 
Percepções de professores de língua inglesa sobre os usos da tecnologia e da internet na aprendizagem de lingua estrangeira

inserida na comunidade, no trabalho, na escola e nas moradias dos brasileiros. Segundo o Ibope Media, existem 105 milhões de internautas brasileiros (10/2013). Conforme a Fecomércio-RJ/Ipsos, o percentual de brasileiros conectados à internet aumentou de $27 \%$ para $48 \%$, entre 2007 e 2011. O principal local de acesso na época dessa pesquisa era a lan house (31\%), seguido da própria casa (27\%) e da casa de parentes de amigos, com 25\%. O Brasil é o $5^{\circ}$ país com o maior número de conexões à Internet ${ }^{3}$.

Segundo os dados da última pesquisa PNAD (Pesquisa Nacional por Amostra de Municípios), do IBGE (Instituto Brasileiro de Geografia e Estatística), publicada em abril de 2016, o Brasil ganhou 9,8 milhões de internautas entre 2013 e $2014^{4}$. Até 2013, por volta de $49 \%$ da população tinha acesso à internet e, no final de 2014, esse número subiu para $54 \%$. A pesquisa mostrou que o acesso à internet via aparelhos celulares ultrapassou, pela primeira vez, o número de acessos feitos via microcomputadores: o número de domicílios que acessavam a internet através de smartphones subiu de 53,6\% para 80\%. Além disso, após anos de aumento vertiginoso (desde 2001), o número de residências que possuem computadores caiu, em 2014, de 49,5\% para 49,2\%. Mesmo assim, o índice é bastante alto se comparado aos 12,6\% de 2001. Essa interrupção no crescimento de moradias com computadores é vista como reflexo do aumento do acesso à internet através de smartphones. Em 2014, quando a pesquisa foi finalizada, 136,6 milhões de brasileiros possuíam pelo menos um telefone celular.

Embora haja diferenças quanto a esses dados em relação às diversas regiões do Brasil, não há dúvida de que o uso da internet está crescendo vertiginosamente, inclusive nos estratos sociais mais baixos. Há programas governamentais que disponibilizam computadores e tablets a professores e alunos de escolas públicas, em locais onde antes notícias atualizadas só chegavam por canais de TV aberta ou rádio. Com o acesso à internet, os professores obtêm informações atualizadas sobre assuntos de países e culturas distantes, o que faz com que esses profissionais fiquem menos presos a materiais didáticos. Através da internet, é possível auxiliarmos os alunos a serem mais independentes em relação a seu aprendizado, pois eles podem realizar tarefas online sozinhos em suas casas ou em suas escolas. Mas logicamente precisamos pensar muito bem em como orientá-los para isso e em como tornar essas atividades realmente producentes e significativas. Stanley (2013) lembra-nos de algo crucial quando optamos por usar tecnologias em aula: a tecnologia não pode ser usada somente porque precisamos estar atualizados. De acordo com esse autor, "many classroom teachers

\footnotetext{
${ }^{3}$ Dados extraídos do site <http://tobeguarany.com/internet-no-brasil/> em 25 mar. 2015.

${ }^{4}$ Dados obtidos no site <http://saladeimprensa.ibge.gov.br/noticias> em 01 jun. 2016.
} 
using technology have anecdotal evidence of their learners being motivated and engaged, and this is often a major reason for using learning technologies" (STANLEY, 2013, p. 2). ${ }^{5}$

O uso da tecnologia em aulas de LE pode ser uma ferramenta de muita interatividade, a internet em especial nos oferece exemplos reais de inúmeras variedades linguísticas do inglês, tanto falado como escrito, e isso, sem dúvida, faz com que haja mudanças significativas no modo como essa língua está sendo ensinada e aprendida. Tanto professores como alunos precisam entender que há várias maneiras de falar, de pronunciar e também de escrever vocábulos do inglês, pois a variação linguística é um fenômeno presente em qualquer língua e as novas tecnologias podem ser uma das melhores ferramentas disponíveis para percebermos isso.

Conforme Barton e Lee (2013), a linguagem tem papel crucial para a compreensão da relação entre tecnologia e atividades cotidianas. É evidente que a linguagem influencia diretamente nas mudanças que ocorrem em nossas vidas; uma delas é que os usuários da internet estão utilizando diversas línguas estrangeiras para se comunicar no mundo online. É por esse motivo que, segundo esses autores, conceitos como "variação", "texto", "discurso", "comunidades de fala", entre outros, devem ser repensados. Entendemos que não é mais tão fácil diferenciar linguagem escrita e falada, já que mensagens escritas enviadas através do Facebook, Whatsapp, Twitter ou e-mail podem ser muito mais coloquiais que diálogos em várias situações de fala.

Segundo Fragoso et al. (2013), quando discorremos acerca da linguagem online, precisamos lembrar que falar sobre a linguagem das novas tecnologias é apenas outra maneira de falar sobre letramento, e que esses conceitos são rapidamente ultrapassados pela agilidade com que as informações circulam na internet. As autoras apontam que

\begin{abstract}
A internet é um universo de investigação particularmente difícil de recortar, em função de sua escala (seus componentes contam-se aos milhões e bilhões), heterogeneidade (grande variação entre as unidades e os contextos) e dinamismo (todos os elementos são permanentemente passíveis de alteração e a configuração do conjunto se modifica a cada momento). (FRAGOSO et al., 2013, p. 55).
\end{abstract}

Por conseguinte, Barton e Lee (2012) são categóricos ao dizer que as práticas de letramento estão em constante mudança, que o letramento pode ser historicamente situado, e que isso visivelmente se aplica às práticas linguísticas online. Por isso, é importante

\footnotetext{
5 "Muitos professores que usam tecnologia possuem somente evidências informais sobre a motivação e o engajamento dos aprendizes; isso é frequentemente o maior motivo para usar tecnologias."
} 
percebermos que o que se tornou mais evidente é o modo como as pessoas estão usando sua L1 ou L2 através das novas tecnologias. Para facilitar o entendimento de suas ideias, Barton e Lee (2013, p. 243) fazem uma lista de atividades que podem ser realizadas na escrita online. O que podemos perceber através desta lista é que todas as atividades podem contribuir para a aprendizagem de uma L2. Resumiremos a seguir algumas atividades sugeridas pelos autores. Ao realizar atividades online, as pessoas têm a oportunidade de:

$\checkmark \quad$ Participar de encontros multilíngues;

$\checkmark \quad$ Explorar múltiplas identidades e diferentes sensos de si mesmas;

$\checkmark \quad$ Refletir mais sobre sua aprendizagem;

$\checkmark \quad$ Tornar públicas práticas vernáculas e, finalmente,

$\checkmark \quad$ Ler mais e escrever mais, mudando suas práticas de leitura e escrita.

Isso é apenas um breve exemplo de como as práticas online podem auxiliar na aprendizagem de línguas. Percebemos que os autores compactuam com as ideias de Fragoso et al. (2013), por enfatizarem que conceitos e teorias que tratam da linguagem online precisam de atualização em uma velocidade talvez nunca antes experimentada.

Além disso, Barton e Lee (2013) assumem que a Web 2.0, diferentemente da Web 1.0, permite que os usuários criem e publiquem conteúdos online em blogs, no Twitter, em enciclopédias como a Wikipédia, no Facebook, entre outros, pois todos esses servidores ou redes sociais dependem de dados que são gerados por seus usuários ${ }^{6}$. Em espaços da Web 2.0, como o YouTube, por exemplo, o posicionamento e a discussão de ideias faz com que as pessoas concordem ou não com as opiniões de outros usuários. Assim, para que essas interações sejam significativas, esses textos precisam ser compreendidos de forma eficaz por aqueles que estão interagindo através desses aplicativos. Isso ocorre em um ambiente plurilíngue, no qual deve haver, sem dúvida, esforço e motivação para a troca de ideias e de conhecimento sobre as questões discutidas. O ganho é evidente para todos. Nunca houve esse compartilhamento de ideias em tempo real, entre cidadãos de lugares tão distantes, falantes de tantas línguas distintas. Dessa forma, é evidente que esses encontros multilíngues geram oportunidades para novos contatos linguísticos, e que esse engajamento que ocorre na comunicação online é, sem dúvida, uma das condições essenciais para o sucesso da aprendizagem de uma língua estrangeira.

\footnotetext{
${ }^{6} \mathrm{Na}$ Web 2.0 é permitido aos usuários publicar conteúdos que eles mesmos criam. Ao contrário, a Web 1.0 é estática, sem nenhuma forma de interatividade com os leitores.
} 


\section{Metodologia empregada e resultados da entrevista online}

De acordo com Paiva (2005), é importante darmos voz aos usuários da internet para que possamos entender melhor o que acontece no mundo virtual. A autora ressalta que "é possível investigar esses contextos, utilizando instrumentos de coleta de dados já conhecidos e agregando a eles as facilidades da rapidez e da sincronia." (PAIVA, 2005, p. 10). No caso desta pesquisa, como nosso foco é refletir sobre a aprendizagem de L2 com o suporte da tecnologia, principalmente a internet, optamos por utilizar um questionário que combinou perguntas estruturadas e semiestruturadas, confeccionada no Google docs ${ }^{7}$. Com esse instrumento de geração de dados, o entrevistador utiliza um questionário com questões cujas alternativas contêm possíveis respostas dos entrevistados e outras nas quais os sujeitos têm mais liberdade e podem ser criativos em suas respostas. Algumas perguntas foram formuladas a partir de princípios de tratamento quantitativo.

Contudo, como estamos expondo procedimentos de análise qualitativa, nosso propósito é apresentar percepções subjacentes ao que está sendo respondido na maior parte das questões da entrevista. Há, nitidamente, em nossa pesquisa, questões totalmente dirigidas e outras que exigem maior liberdade de expressão dos entrevistados. Essa questão ficará clara no decorrer deste artigo.

Todos os sujeitos são professores de língua inglesa, tanto de adultos como de crianças, em instituições de ensino básico ou superior, cursos livres de idiomas, ou são professores autônomos. A maior parte desses profissionais é do Rio Grande do Sul; entretanto, há sujeitos de outros estados, como Pernambuco, Rio de Janeiro e Santa Catarina. Como detalharemos a seguir, muitos deles são graduados em Letras e já trabalham como professores de inglês há mais de 5 anos. É interessante ressaltar que $77 \%$ deles afirmam aprimorar seus conhecimentos de Língua Inglesa estudando as 4 habilidades linguísticas por conta própria; apenas $10 \%$ estão matriculados em algum curso de inglês ou escola de idiomas e somente $22 \%$ possuem algum curso de pós-graduação na área de Letras. Outro fator interessante é que $8 \%$ dos sujeitos são sinceros em dizer que nunca leem livros ou artigos sobre aquisição de segunda língua. Isso é, sem dúvida, um dado bastante preocupante. No decorrer deste trabalho, iremos nos ater detalhadamente a questões específicas sobre ensino de inglês e tecnologia, como já informado anteriormente.

\footnotetext{
${ }^{7}$ Disponível em: <https://www.google.com/intl/pt-BR/drive/>. Acesso em: 23 mai. 2016.
} 
Considerando-se os objetivos deste trabalho e também as análises sobre metodologia de pesquisa, de autores como Minayo (1993), Prodanov e Freitas (2009) e também de Lakatos e Marconi (2010), observamos que esta pesquisa apresenta características de uma pesquisa qualitativa, pois busca compreender fenômenos complexos de natureza subjetiva. Nesse sentido,

[...] a entrevista é o procedimento mais usual no trabalho de campo. Através dela, o pesquisador busca obter informes contidos na fala dos atores sociais. Ela não significa uma conversa despretensiosa e neutra, uma vez que se insere como meio de coleta dos fatos relatados pelos atores, enquanto sujeitos-objeto da pesquisa que vivenciam uma determinada realidade que está sendo focalizada. (MINAYO, 1993, p. 57).

As respostas do questionário ${ }^{8}$ foram enviadas por e-mail e pelo Facebook. Nenhum sujeito da pesquisa respondeu às perguntas em cópia física. $\mathrm{O}$ instrumento foi elaborado com 11 perguntas fechadas e 1 pergunta aberta. 81 professores enviaram suas observações. Quanto ao perfil desses profissionais, resumiremos a seguir as informações mais relevantes. Nosso maior interesse é conhecer suas principais preocupações e percepções sobre o uso da internet e como tal ferramenta pode auxiliar na aprendizagem de língua estrangeira.

A primeira questão ${ }^{9}$ refere-se ao tempo de atuação dos sujeitos como professores de inglês: 58\% dos entrevistados atuam na profissão há mais de 5 anos, 33\% entre 1 e 5 anos, e somente $9 \%$ há menos de um ano. Já a segunda questão, acerca da formação dos professores, nos surpreendeu: 69\% sujeitos possuem graduação em Letras. Fazemos essa reflexão porque há inúmeros profissionais no país que atuam como professores de inglês, em cursos livres e em escolas de ensino básico, que não possuem graduação na área ou alguma outra graduação. No Brasil, ainda é grande o número de professores de língua inglesa que tiveram algum tipo de contato com a língua estrangeira no exterior, mas que nunca estudaram metodologias de ensino ou disciplinas com foco na Aquisição de Segunda Língua (Second Language Acquisition - SLA) ou aprendizagem de línguas estrangeiras.

A terceira questão solicita que os sujeitos informem seu nível linguístico em inglês. Para essa pergunta, 79\% afirmaram ter nível avançado, $21 \%$ assumiram somente ter nível intermediário e nenhum participante relatou ter nível básico de conhecimento de inglês.

Na pergunta 4, os sujeitos são questionados sobre sua carga horária: $31 \%$ trabalham mais de 30 horas semanais, 23\% entre 21 e 30 horas e $46 \%$ atuam menos de 20 horas. Podemos conjecturar aqui que quase metade dos professores entrevistados possui tempo

\footnotetext{
${ }^{8}$ Os sujeitos não precisavam responder a todas as questões.

${ }^{9} \mathrm{O}$ questionário encontra-se anexo ao final deste artigo.
} 
suficiente para preparar suas aulas, isso se não atuarem como professores de outras disciplinas ou ainda em outras áreas profissionais. Para complementar essa ideia, a questão número 5 investiga o tempo despendido para preparação e correção de atividades. Somente $2 \%$ dos entrevistados despendem mais de 20 horas para essas tarefas. A grande maioria (80\%, ou seja, 65 sujeitos) respondeu utilizar no máximo 10 horas semanais para preparo de aula e $17 \%$ despende entre 11 e 20 horas.

As respostas à questão 6 também foram relativamente inesperadas. Nela, foi questionado se os professores utilizavam livros de apoio em suas aulas: somente 14\% disseram não utilizar algum livro texto. Compreendemos que o uso de um bom livro texto de inglês pode facilitar muito o preparo das aulas e talvez seja por isso que os professores entrevistados revelaram despender uma pequena quantidade de horas para essa atividade. As quatro questões a seguir (4 fechadas e 1 aberta) serão discutidas mais detalhadamente, pois remetem diretamente ao uso da tecnologia e da internet em sala de aula.

Questão 7 - Quais dos recursos a seguir você utiliza em sala de aula?

a) computador/internet em geral;

b) Filmes, seriados ou vídeos;

c) Músicas em cds ou em vídeos do YouTube;

d) Jogos online ou outros jogos;

e) Revistas e jornais.

Nessa questão, os participantes podiam marcar quantas opções quisessem. Assim, obteve-se $23 \%$ na resposta $A ; 20 \%$ na $B ; 22 \%$ na $C$; $20 \%$ na $D$; e uma parcela um pouco menor na E: $14 \%$ dos professores. Diante disso, percebemos que atividades com revistas e jornais estão perdendo força em sala de aula. Parece-nos que realmente os professores estão optando por aumentar o número de atividades mediadas pelo computador e há uma tendência de que, aos poucos, atividades online irão substituir tarefas antes realizadas com papel, cartolina, cola, figuras de revistas, anúncios e matérias de jornais impressos, por exemplo. Obviamente, se há disponibilidade de computadores, tablets ou celulares em aula ou em um laboratório, torna-se muito mais fácil, rápido e barato acessar anúncios, reportagens e imagens online.

O uso de vídeos em geral também se tornou muito mais fácil com os avanços da tecnologia: não há mais necessidade de locação de filmes em locadoras de vídeo porque muitos filmes de todos os gêneros estão disponíveis na internet, com legendas em sua língua original ou já traduzidas. Para corroborar essas observações, vejamos o que os sujeitos da pesquisa responderam na pergunta seguinte: 
Percepções de professores de língua inglesa sobre os usos da tecnologia e da internet na aprendizagem de lingua estrangeira

Questão 8 - Você utiliza a internet em suas aulas?

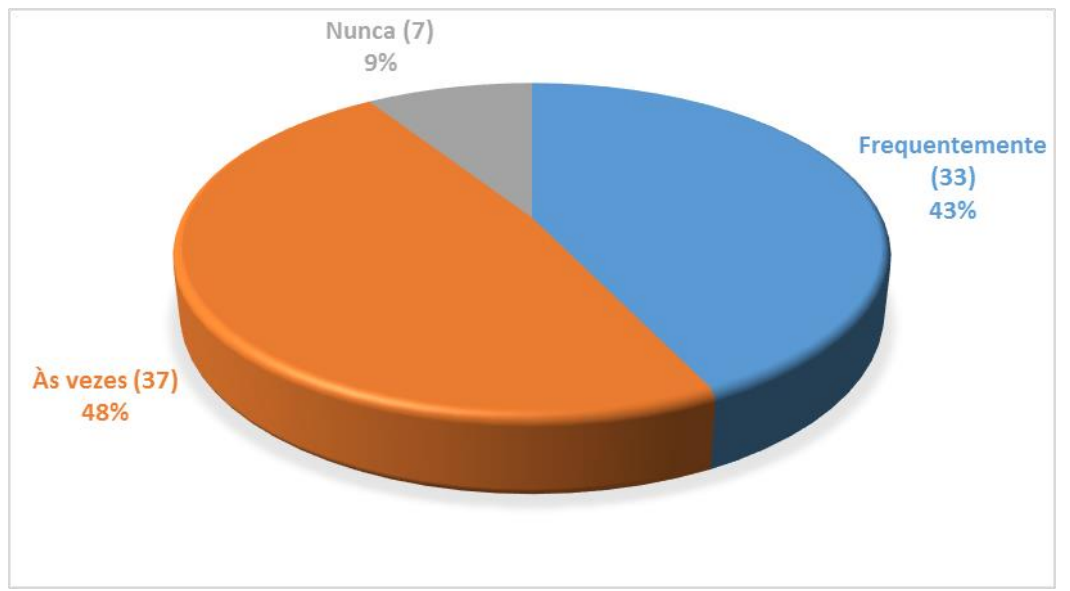

Percebemos que um número pequeno de professores (7) afirma nunca fazer uso da internet em aula. Observamos também que alguns participantes não responderam essa questão, assim como a questão a seguir. Mesmo assim, 70 indivíduos declaram utilizar a internet de alguma forma, mesmo que esporadicamente em suas aulas. Na próxima questão, é pedido somente àqueles que declaram usar a internet em aula que marquem os tipos de sites acessados para auxiliar na aprendizagem do inglês.

Questão 9 - Se você usa a internet como suporte em suas aulas, marque todos os itens que você utiliza (tipos de sites, correio eletrônico, rede social etc.):

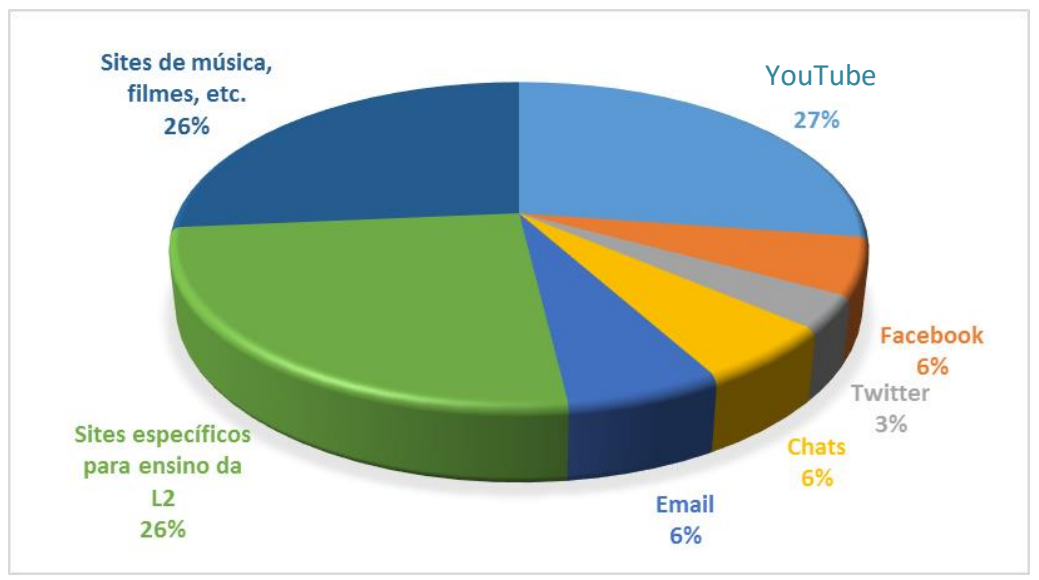

Sobre a questão acima, observamos que a preferência dos professores recai sobre sites específicos de ensino de línguas, vídeos do YouTube e sites que apresentam atividades variadas com músicas, extratos de filmes, jogos, cartuns etc. O Facebook, a rede social mais acessada no mundo, ainda não é considerada pela maior parte dos participantes como uma ferramenta capaz de auxiliar na aquisição de uma língua estrangeira: somente 12 professores o 
utilizam em aula. Não perguntamos a eles, porém, de que forma exatamente estão utilizando esses sites, e-mails ou redes sociais. Em uma próxima pesquisa, é interessante que essa questão se faça presente para que tenhamos um maior entendimento de como essas atividades estão sendo realizadas em aula ou fora do ambiente de ensino formal. As questões 10 e 11 se complementam e nos revelam que os professores entrevistados estão abertos a novas maneiras de ensinar inglês. Não deixa de ser surpreendente o fato de nenhum professor discordar de que a internet pode, de alguma forma, ajudar na aquisição de línguas estrangeiras.

Questão 10 - Você concorda que a internet possa auxiliar na aprendizagem de línguas?

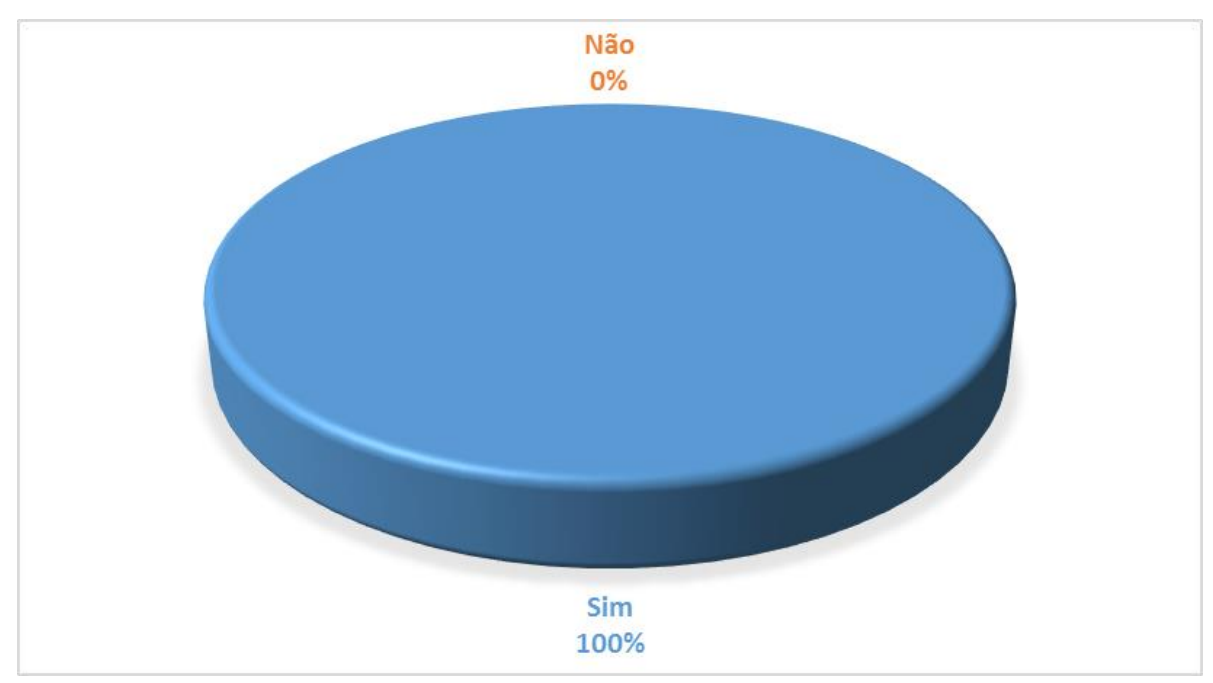

Na questão 11, porém, 4 sujeitos declaram não perceber que a internet possa mudar o modo como ensinamos ou aprendemos uma língua, embora concordem que a internet possa auxiliar esse processo.

Questão 11 - Em sua opinião, o uso da internet em sala de aula pode mudar o modo como ensinamos e aprendemos uma língua estrangeira? 


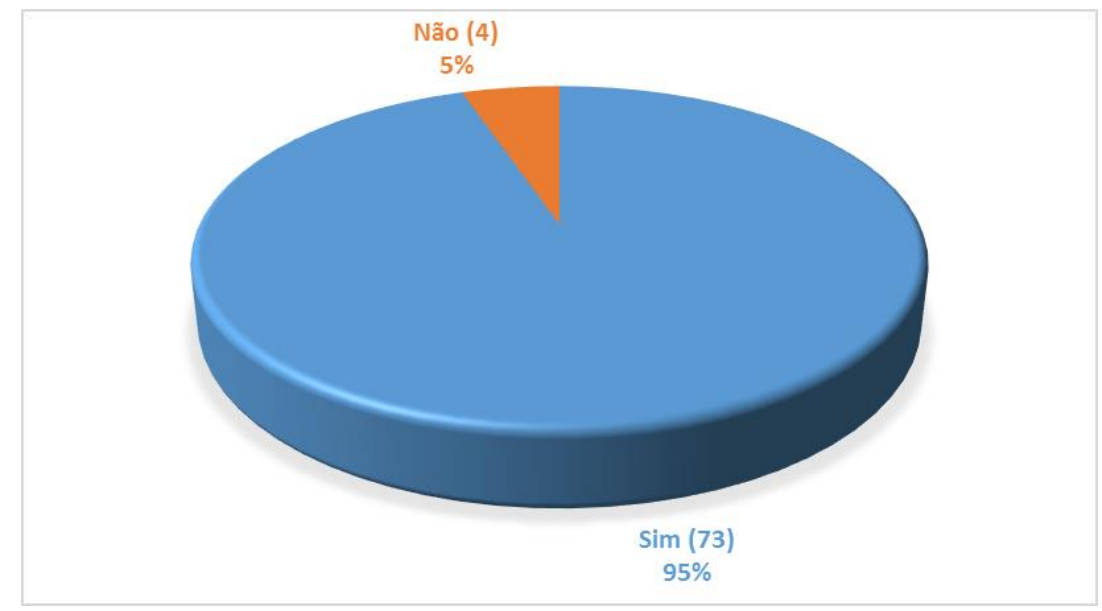

Entendemos a opinião desses professores, pois percebemos que o uso de tecnologias no ensino pode se tornar insatisfatório se não forem utilizadas para oferecer maior interatividade e fonte inesgotável de usos de diferentes variantes da língua alvo. Quanto a isso, concordamos com Stanley (2013), pois “Technology can be a highly engaging and interactive tool, providing a source of real language, both written and spoken, in the classroom, and motivating learners to produce more language than they otherwise might have done." (STANLEY, 2013, p. 2). ${ }^{10}$

A questão 12, por fim, pede que os sujeitos deem suas sugestões respondendo livremente à seguinte questão: “Alguns professores se opõem ao uso da internet em sala de aula porque percebem que isso pode desviar a atenção dos alunos na realização das tarefas. Você tem alguma sugestão do que pode ser feito para que isso não aconteça durante as atividades propostas?". Aqui, principalmente, por questão de espaço, iremos detalhar somente parte dessas respostas, até porque muitas opiniões dos sujeitos são semelhantes. Uma das observações mais reportadas foi sobre o planejamento das aulas com o uso da internet: sem um roteiro claro a ser cumprido e sem que os professores esclareçam exatamente o que os alunos devem fazer, uma aula com o suporte de qualquer tecnologia não terá sucesso. Alguns professores sugerem que a turma seja dividida em grupos pequenos, com no máximo 3 alunos por computador. Há também a preocupação com a possibilidade de os aprendizes (principalmente crianças e adolescentes) acessarem quaisquer sites. Segundo alguns sujeitos, é necessário que se restrinja o acesso para que os alunos não percam o foco. Um sujeito é bastante categórico ao dizer que a única maneira de fazer com que os aprendizes façam as atividades propostas é dispor os computadores na sala de forma que o professor consiga

10 "A tecnologia pode ser uma ferramenta altamente interativa e engajada, oferecendo fonte de linguagem real, escrita e falada, na sala de aula, motivando os aprendizes a produzir mais linguagem do que eles poderiam ter produzido de outra forma." 
circular e enxergar os sites consultados pelos alunos. Por outro lado, também de maneira enfática, dois sujeitos afirmam que não há a menor possibilidade de se usar a internet em turmas de 30 ou 40 alunos, por exemplo. Há também aqueles que consideram a internet algo maravilhoso, mas que não conseguem perceber como usá-la em sala de aula. Outros, por sua vez, afirmam que não há como não levar em conta o uso da internet, atualmente, em aulas de línguas, e que, preferencialmente, os professores preparem aulas que desafiem os alunos a encontrar respostas que não poderiam achar em seus livros, por exemplo.

No quadro abaixo, apresentaremos parte das respostas dos professores entrevistados. Evitaremos, porém, respostas muito semelhantes ou repetidas. Também houve respostas que simplesmente expunham que os sujeitos não tinham nenhuma sugestão a dar. Eles apenas responderam "Não".

Quadro 1 - Respostas da questão 12

\begin{tabular}{|c|c|}
\hline \multicolumn{2}{|r|}{ Respostas da questão 12} \\
\hline S1 & $\begin{array}{l}\text { O professor deve apresentar sempre um roteiro a ser cumprido em quaisquer } \\
\text { situações, principalmente quando a atividade envolver a internet. }\end{array}$ \\
\hline S2 & $\begin{array}{l}\text { Acho que a internet não revoluciona a sala de aula; pode-se dar uma aula } \\
\text { extremamente maçante usando um milhão de recursos online, ou dar uma aula } \\
\text { excelente sem auxílio algum. }\end{array}$ \\
\hline S3 & $\begin{array}{l}\text { Normalmente divido a turma em pequenos grupos e cada um deles recebe uma } \\
\text { atividade que será realizada na internet. Realizo pequenas competições e os alunos } \\
\text { se sentem bastante motivados. }\end{array}$ \\
\hline S4 & $\begin{array}{l}\text { Atividades na internet não desviam a atenção do aluno, desde que a proposta na } \\
\text { realização das tarefas seja clara e objetiva. }\end{array}$ \\
\hline S5 & $\begin{array}{l}\text { Não pode ser permitido que os alunos tenham acesso a qualquer site; é preciso que } \\
\text { se restrinjam as páginas que podem ser visitadas. }\end{array}$ \\
\hline S6 & $\begin{array}{l}\text { Todos estamos muito conectados à internet. É praticamente impossível não levar } \\
\text { em conta o uso dessa ferramenta em sala de aula. Os professores precisam se dar } \\
\text { conta disso o quanto antes! }\end{array}$ \\
\hline S7 & $\begin{array}{l}\text { As atividades devem ser bem elaboradas, com objetivos específicos. Como a aula } \\
\text { deve ser "task oriented", não vejo problema de os alunos acessarem outras janelas. }\end{array}$ \\
\hline S8 & $\begin{array}{l}\text { Acho que a solução é introduzir o elemento "competição" entre os alunos, } \\
\text { principalmente se forem adolescentes. A motivação faz com que eles se foquem } \\
\text { na atividade proposta. }\end{array}$ \\
\hline
\end{tabular}




\begin{tabular}{|c|c|}
\hline S9 & $\begin{array}{l}\text { Não tenho nenhuma sugestão. Os alunos ainda não estão preparados para terem } \\
\text { aulas online. }\end{array}$ \\
\hline S10 & $\begin{array}{l}\text { Todas as atividades devem ter tempo limitado para sua execução. Dessa forma, é } \\
\text { mais difícil que o aluno não realize a tarefa. }\end{array}$ \\
\hline S11 & $\begin{array}{l}\text { Se as tarefas forem bem explicadas aos alunos, penso que não há como não se } \\
\text { obter ganhos com o uso da internet para a aprendizagem de línguas. }\end{array}$ \\
\hline S12 & $\begin{array}{l}\text { Creio que se a tarefa for significativa para os aprendizes, o foco nunca é perdido. } \\
\text { Também deve-se delimitar o tempo de início e de fim das tarefas. }\end{array}$ \\
\hline S13 & $\begin{array}{l}\text { O professor tem que estar o tempo todo atento para que os alunos não se distraiam } \\
\text { nas redes sociais. O que se pode fazer é criar atividades usando essas redes. }\end{array}$ \\
\hline S14 & $\begin{array}{l}\text { O educador deve deixar claro que é o futuro deles que está em jogo e que, após a } \\
\text { aula, eles podem se distrair nas redes sociais. }\end{array}$ \\
\hline S15 & $\begin{array}{l}\text { Atividades que antes eram realizadas com cópia física foram aos poucos } \\
\text { substituídas por atividades mais interativas com o auxílio da internet. Sem dúvida, } \\
\text { os professores deveriam ter mais iniciativa e se esforçar para usar a internet com } \\
\text { mais frequência. }\end{array}$ \\
\hline S16 & $\begin{array}{l}\text { Toda tarefa deve ter um objetivo pedagógico muito claro. Usar vídeos e música } \\
\text { sem nenhum propósito pode acrescentar muito pouco para os aprendizes. }\end{array}$ \\
\hline S17 & $\begin{array}{l}\text { A internet está presente na sala de aula, de qualquer forma, pois muitos alunos } \\
\text { trazem tablets, notebooks e celulares para a escola. O importante é não fazer com } \\
\text { que esses aparatos tecnológicos se tornem inimigos dos professores. }\end{array}$ \\
\hline S18 & $\begin{array}{l}\text { Em minha opinião, o melhor é o professor usar o quadro digital ou o projetor. Os } \\
\text { alunos se desfocam muito das tarefas se usam computadores individualmente ou } \\
\text { em grupos. }\end{array}$ \\
\hline S19 & $\begin{array}{l}\text { Acredito que uma solução é posicionar os computadores de forma que o professor } \\
\text { possa circular na sala e ver os sites que os alunos estão acessando. }\end{array}$ \\
\hline S20 & $\begin{array}{l}\text { A internet é uma ferramenta maravilhosa, mas usá-la em sala de aula com uma } \\
\text { turma de mais de } 40 \text { alunos é praticamente impossível. Uma boa parte da turma } \\
\text { não fará as atividades e ficarão olhando outros sites quaisquer. }\end{array}$ \\
\hline
\end{tabular}

Fonte: Elaborado pela autora 
É interessante notar a percepção de muitos professores de que precisamos proporcionar aos alunos situações nas quais eles realmente precisem da internet para a realização das atividades e que essas tenham sempre tempo limitado para serem feitas. O que podemos perceber através dessas respostas é que há professores interessados em saber como podem aperfeiçoar suas aulas, com o uso da tecnologia e, mesmo demonstrando terem dúvidas quanto a isso, notamos que muitos estão buscando respostas e se sentem motivados com o trabalho que realizam.

\section{Considerações finais}

Segundo Mike (1996), o uso da internet promove uma melhora em várias habilidades dos aprendizes. Quando o professor pede aos alunos que busquem informações específicas, por exemplo, isso requer conhecimento lógico, pois eles precisam procurar, escolher, descartar e avaliar as informações selecionadas. Dessa forma, a aquisição da gramática e do vocabulário acontece de modo natural e rápido.

Apesar dos obstáculos existentes em qualquer método ou formas de aprender uma segunda língua, o potencial que há na utilização da internet é muito grande. Embora seja um ambiente virtual, as pessoas conseguem chegar a um alto nível de interação, principalmente através da leitura e da escrita, o que muitas vezes não ocorre em sala de aula. De acordo com Freeman e Capper (1999), a quantidade de assuntos e materiais encontrados na web potencializa e agiliza atividades feitas em aula. A partir dessas tarefas, os professores têm também a possibilidade de solicitar que os aprendizes as finalizem em casa ou no laboratório de informática da escola. Além disso, nunca foi tão fácil trabalhar com notícias em tempo real. A gama de assuntos que podem ser pesquisados na internet é incomensurável, mas evidentemente todas as tarefas devem ser monitoradas pelo professor. Os computadores devem ter sido testados e todas as atividades realizadas anteriormente. Da mesma forma, o professor precisa sempre ter atividades extras para qualquer eventualidade, pois sabemos que a tecnologia pode falhar por vários motivos.

O uso da internet como suporte para aprendizagem de línguas é algo que não tem mais como ser excluído das discussões sobre a aquisição de L2. Cada vez mais, aprendizes e professores utilizam diversos aplicativos em smartphones, tablets e notebooks, que os ajudam a aprender e exercitar as quatro habilidades linguísticas de uma língua estrangeira. Há uma infinidade de sites, de tradutores online, redes sociais e aplicativos que podem auxiliar os professores a tornarem suas aulas mais dinâmicas e significativas. $\mathrm{O}$ que percebemos nesta 
pesquisa foi que a maioria dos professores aqui entrevistados tem a intenção de entender melhor como poderiam utilizar a internet e as novas tecnologias em suas aulas. A maior preocupação de muitos deles é saber como fazer isso de forma a trazer realmente algo novo e produtivo para seus alunos. Muitos deles ainda têm dúvidas acerca do uso dessas tecnologias.

Realmente, temos que concordar que há poucos artigos e livros que mostram de maneira clara aos professores como criar atividades e como utilizar a internet em sala de aula. Por isso, é necessário que mais pesquisas sejam realizadas com o objetivo de compreender melhor como o uso da tecnologia e da internet pode se tornar mais efetivo dentro e fora de sala de aula, com sugestões de atividades, estudos comparativos etc. É responsabilidade do professor saber como utilizar materiais e ferramentas disponíveis na internet. Segundo Zhao (2005, p. 454), hoje a maior parte das pesquisas precisam ser voltadas para a confecção das atividades e para os aprendizes e não para questões técnicas de informática, por exemplo.

Percebemos que uma das coisas mais importantes no momento é estarmos abertos para entender pelo menos um pouco de todas estas mudanças tecnológicas que surgem aos turbilhões no nosso dia a dia. E, assim, a partir dessa percepção, incluirmos a internet gradativamente em nossas aulas, tornando-as mais significativas para nossos aprendizes.

GRÉGIS, Rosi Ana. Perceptions of English teachers about the uses of technology and internet on foreign language learning. Revista do GEL, São Paulo, v. 13, n. 2, p. 118-137, 2016.

Abstract: The main goal of this work is to discuss the perceptions of teachers of English as a foreign language on how internet and new technologies have influenced language learning, either in the classroom or in informal environments of learning. Authors such as ZHAO (2005), LAI (2005) and STANLEY (2012) feel that the use of blogs, chats, twitter, e-mails, sites and internet videos, among others, can contribute for a better learning of English. Thus, it is not surprising that, in this research, most of the interviewed English teachers believe that new technologies can change the way we learn and teach foreign languages.

Keywords: Language learning; Technology; Internet.

\section{Referências}

BARTON, D.; LEE, C. Redefining vernacular literacies in the age of Web 2.0. Applied Linguistics, 33 (3), p. 282-298, 2012.

Linguagem online: textos e práticas digitais. São Paulo: Parábola, 2013. 
FRAGOSO, S. et al. Métodos de pesquisa para internet. Porto Alegre: Sulina, 2013.

FREEMAN, M. A.; CAPPER, J. M. Exploiting the web for education: an anonymous asynchronous role simulation. Australian Journal of Educational Technology, 15 (1), 1999, p. 95-116.

IBGE. Disponível em: <http://saladeimprensa.ibge.gov.br/noticias>. Acesso em: 1 jun. 2016.

Internet no Brasil. Disponível em: <http://tobeguarany.com/internet-no-brasil/>. Acesso em: 25 mar. 2015.

KROONENBERG, N. Developing communicative and thinking skills via electronic mail. TESOL Journal, 4 (2), p. 24-27, 1995.

LAI, C. The role of communicative practices and talking with and through the computer. In: ZHAO, Y. (Org.). Research in technology and second language learning: developments and directions. Connecticut: Information Age Publishing, 2005.

LAKATOS, E. M.; MARCONI, M. A. Fundamentos de metodologia científica. São Paulo: Atlas, 2010.

MIKE, D. Internet in the schools: a literacy perspective. Journal of Adolescent and Adult Literacy, 40 (1), p. 1-13, 1996.

MINAYO, M. C. S. (Org.). Pesquisa social: teoria, método e criatividade. Rio de Janeiro: Vozes, 1993.

PAIVA, V. L. M. O. A pesquisa sobre interação e aprendizagem de línguas mediadas pelo computador. Calidoscópio, São Leopoldo, v. 3, n. 1, p. 5-12, jan./abr. 2005. Disponível em: <http://www.veramenezes.com/cmc.htm>. Acesso em: 27 fev. 2014.

PRODANOV, C.; FREITAS, E. Metodologia do trabalho científico: métodos e técnicas do trabalho acadêmico. Novo Hamburgo: Editora Feevale, 2009.

STANLEY, G. Language learning with technology: ideas for integrating technology in the classroom. Cambridge: Cambridge University Press, 2013.

ZHAO, Y. (Org.). Research in technology and second language learning: developments and directions. Connecticut: Information Age Publishing, 2005.

Submetido em 17/09/2015

Aceito em 18/05/2016. 


\section{ANEXO}

\section{Ensino e aprendizagem de Língua Inglesa - RS}

1. Há quanto tempo você é professor de inglês? *

( ) Há menos de 1 ano

( ) Entre 1 e 5 anos

( ) Mais de 5 anos

2. Você é graduado em Letras? $*$

( ) $\operatorname{Sim}$

( ) Não

3. Qual o seu nível linguístico de língua inglesa? *

( ) Básico

( ) Intermediário

( ) Avançado

4. Quantas horas por semana você trabalha como professor de inglês? *

( ) 1 a 20

( ) 21 a 30

( ) Mais de 30

5. Quantas horas por semana você despende para preparar suas aulas e corrigir tarefas?

( ) 0 a 10

( ) 11 a 20

( ) Mais de 20

6. Você e seus alunos utilizam algum livro de apoio em aula? *

(Exemplos: New Interchange, Headway, Top Notch, English File)

( ) $\operatorname{Sim}$

( ) Não 
7. Quais dos recursos a seguir você utiliza em sala de aula? *

(marque todos os itens que desejar)

( ) Computador/internet

( ) Filmes, seriados ou vídeos da internet

( ) Músicas em cds ou vídeos do YouTube

( ) Jogos online, tabuleiros, questionários em pares, crosswords etc.

( ) Revistas e jornais

8. Você utiliza a internet em suas aulas?

( ) Frequentemente

( ) Às vezes

( ) Nunca.

9. Se você usa a internet em suas aulas, quais tipos de site você utiliza? (marque todos os itens que desejar)

( ) YouTube

( ) Facebook

( ) Twitter

( ) Email

( ) Sites de ensino de língua estrangeira (BBC English, Cambridge University Press, Oxford University Press, English Café etc.)

( ) Sites específicos com atividades de música, filmes, puzzles etc. (exemplos de sites)

10. Você concorda que a internet possa auxiliar na aprendizagem de línguas?

( ) $\mathrm{Sim}$

( ) Não

11. Em sua opinião, o uso da internet em sala de aula pode mudar o modo como ensinamos e aprendemos uma língua estrangeira?

( ) $\operatorname{Sim}$

( ) Não 
Percepções de professores de língua inglesa sobre os usos da tecnologia e da internet na aprendizagem de lingua estrangeira

12. Alguns professores se opõem ao uso da internet em sala de aula porque percebem que isso pode desviar a atenção dos alunos na realização das tarefas. Você tem alguma sugestão de o que fazer para que isso não aconteça durante as atividades propostas? 